\title{
OS SERVIÇOS ECOSSISTEMICOS E A GESTÃ̃ DO USO PÚBLICO NAS UNIDADES DE CONSERVAÇÃO NA ILHA DE SANTA CATARINA, SC.
}

\author{
Washington Ferreira ${ }^{1}$
}

\section{RESUMO}

Descrevem-se o processo de pesquisa e os resultados preliminares da aplicação da análise dos serviços ecossistêmicos na gestão do uso público das Unidades de Conservação (UCs) na Ilha de Santa Catarina. Estas UCs apresentam diferentes atrativos e possibilidades de acesso e uso público para a sociedade, os quais são parte do objeto de sua gestão socioambiental. Foi desenvolvida a modelagem conceitual dos principais ecossistemas locais, evidenciando-se a estrutura e os fluxos preponderantes dentre os mesmos. Logo após, foram integrados os serviços ecossistêmicos (suporte, provisão, regulação, cultural) proporcionados pelas diferentes unidades ambientais, bem como aspectos da gestão do uso público nestas UCs (forças motrizes, atividades impactantes). Após esta sistematização, constatou-se a similaridade e recorrência de problemas nos diferentes ambientes, suas causas geradoras (infraestrutura urbana e construção civil) e principais atores sociais envolvidos (setor imobiliário e turístico), assim como a influencia de determinadas atividades e atores sobre alguns dos ecossistemas locais mais afetados (praias arenosas e manguezais). Tais resultados indicam a necessidade de efetiva complementação das estratégias de ação das distintas agencias governamentais envolvidas na gestão ambiental das UCs na Ilha de Santa Catarina, através de um processo integrado para o mosaico de UCs da ilha. Neste processo de manejo integrado, faz-se necessário a incorporação de uma nova visão estratégica sobre o papel do uso público destas UCs, na qual as comunidades do entorno e a sociedade envolvente possam efetivamente se sentir incluídas e parceiras, em substituição ao modelo predominante de gestão, centralizado e excludente, que não atende plenamente aos objetivos propostos e contribui para a manutenção e acirramento de conflitos socioambientais. Esta reintegração conceitual, com base na ecologia da paisagem (como construção da cultura sobre a base natural), permite-nos uma maior aproximação entre os objetivos da conservação ambiental e as necessidades das atividades circundantes, especialmente quando consideramos a dinâmica dos processos socioambientais, extremamente diversos e catalisados por forçantes externas em rápida e contínua transformação.

Palavras chave: Unidades de conservação, uso público, planejamento e gestão, serviços ecossistêmicos, Ilha de Santa Catarina.

\section{RESUMEN}

Se describen el proceso de investigación y resultados preliminares del análisis de la aplicación de los servicios de los ecosistemas en la gestión del uso público de las áreas protegidas (UCs) en la Isla de Santa Catarina; estas áreas protegidas tienen diferentes atracciones y la accesibilidad y el uso público de la sociedad, que son parte del objeto de su gestión ambiental. Se desarrolló el modelado conceptual de los principales ecosistemas locales, mostrando la estructura y los flujos predominantes entre ellos. Después, los servicios

${ }^{1}$ Bolsista (Estágio de Pós-doutorado) da CAPES (Projeto No A047/2013). Programa de Pós-Graduação em Geografia da UFSC - Universidade Federal de Santa Catarina, Brasil. E-mail: thalassoching@yahoo.com.br 
ambientales proporcionados por diferentes unidades ambientales (soporte, provisión, regulación, culturales) se han integrado, así como los aspectos del uso público (fuerzas motrices, que afectan a las actividades) de manejo de estos áreas protegidas. Después de esta sistematización, se percibió la similitud y la recurrencia de problemas en diferentes entornos, sus causas generadoras (infraestructura urbana y la construcción) y de los principales actores sociales implicados (sector inmobiliario y la industria del turismo), así como la influencia de ciertas actividades y actores sobre algunos de los ecosistemas locales más afectados (manglares y playas de arena). Estos resultados indican la necesidad de complementación eficaz de las estrategias de acción de los distintos organismos gubernamentales que participan en la gestión ambiental de las áreas protegidas en la Isla de Santa Catarina, a través de un proceso integrado para el mosaico de UCs de la isla, y dentro de la casa uno de ellos, por todos sus ambientes. En esto proceso de gestión integrada, es necesario incorporar una nueva visión estratégica del papel del uso público de estas áreas protegidas, en las que las comunidades de los alrededores y la sociedad circundante efectivamente pueden sentirse incluida, reemplazando el modelo imperante de gestión, centralizado y excluyente, que no cumple plenamente los objetivos propuestos y contribuye al mantenimiento u agravamiento de los conflictos socio-ambientales. Esta reintegración conceptual, basado en la ecología del paisaje (como la construcción de la cultura por sobre la base natural), nos permite una relación más estrecha entre los objetivos de conservación del medio ambiente y las necesidades de las actividades en torno, sobre todo si tenemos en cuenta la dinámica de los procesos ambientales, en gran medida diversa y catalizada por forzamientos externos en rápida y continua transformación.

Palabras-claves: Áreas protegidas, uso público, la planificación y la gestión, servicios de los ecosistemas, Isla de Santa Catarina.

\section{INTRODUÇÃO}

O planejamento, implementação e manejo das diferentes categorias de Unidades de Conservação (UCs) constituem parte essencial das estratégias de conservação da biodiversidade, ao estabelecerem frações do território que comportem amostras representativas de distintos ecossistemas, seus componentes e processos. Além do seu valor intrínseco, as UCs também desempenham relevantes serviços socioeconômicos e culturais, pelo fato de proteger o patrimônio natural compartilhado, ao qual se encontra associada à identidade cultural e muitas das atividades econômicas de comunidades nos seus limites e entorno, e de influenciarem positivamente o fluxo de bens, energia e serviços das sociedades envolventes e mesmo de outras, por vezes, muito distantes destas áreas.

A Avaliação Ecossistêmica do Milênio define quatro categorias básicas de serviços ecossistêmicos ("benefícios que as pessoas obtêm dos ecossistemas"), incluindo serviços de provisão (alimentos, água, madeira, fibras e recursos genéticos), regulação (do clima, de inundações, doenças, qualidade da água, tratamento de resíduos), suporte (formação do solo, polinização e ciclagem de nutrientes) e culturais (recreação, apreciação estética e realização espiritual) (KOSMUS, RENNER, ULRICH, 2012: 13). O reconhecimento sobre o significado dos serviços ecossistêmicos para a manutenção dos processos vitais e das atividades socioeconômicas é relativamente recente. Enquanto campo de pesquisa transdisciplinar, tem recebido aportes desde a ecologia de sistemas, porém tem alcançado maior especificidade e 
rigor conceitual após as premissas sobre o ecodesenvolvimento, com a inserção dos princípios ecológicos como base do planejamento econômico (SANTOS, 2014: 21).

A Ilha de Santa Catarina, sede do município de Florianópolis (SC, região sul do Brasil), comporta um conjunto de UCs que integram uma série de unidades ambientais altamente vulneráveis e significativas para a conservação da zona costeira do país, os quais proporcionam relevantes serviços ecossistêmicos à sociedade. Estes serviços ecossistêmicos podem contribui eficazmente na percepção coletiva e discussão sobre o uso público nas UCs, como outra abordagem, visando sua utilização como ferramenta de análise e aperfeiçoamento da gestão destas áreas e sistemas.

\section{MATERIAL E MÉTODOS}

Visando uma primeira aproximação sistêmica, direcionada as especificidades da Ilha de Santa Catarina, foi desenvolvida a modelagem conceitual da estrutura e dos principais ecossistemas locais (NIEHUES, 2014: 43). A partir deste modelo, vem sendo desenvolvida a análise dos serviços ecossistêmicos proporcionados pelo conjunto de seus ambientes (ASMUS; SCHERER; OLIVEIRA, 2014: 05), por meio da construção coletiva de uma matriz, na qual são discriminados os atributos, serviços e beneficiários de cada um dos ambientes analisados. Aprofundando o presente estudo de caso (sensu YIN, 2005: 38), através da análise documental, foi compilada a informação relativa à criação e distribuição espacial do conjunto das UCs na Ilha de Santa Catarina. Analisaram-se, para cada uma das unidades ambientais, os principais serviços ecossistêmicos, os benefícios por eles proporcionados, e os atores sociais e as atividades econômicas mais diretamente beneficiadas; estes aspectos foram condensados para o conjunto de unidades ambientais. Na terceira etapa, foram integrados os usos públicos (efetivos e potenciais) dos serviços ecossistêmicos, e tensores na gestão destas UCs (forças motrizes, atividades impactantes). Discutem-se os impactos socioambientais derivados do uso público dos serviços ecossistêmicos nestas UCs e algumas das suas implicações e possibilidades alternativas na sua gestão.

\section{RESULTADOS E DISCUSSÃO}

\section{$\underline{\text { As Unidades de Conservação }}$}

A análise documental relativa ao processo de criação das Unidades de Conservação na Ilha de Santa Catarina e entornos (BRASIL, 2000; FATMA, 2014; FLORIPA AMANHA, 2015; ICMBIO, 2013, 2014; PMF, 2014; TIRLONI, 2015) resultou em um conjunto de 19 UCs, sendo 06 de âmbito federal (APA da Baleia Franca ${ }^{2}$, APA de Anhatomirim ${ }^{3}$, ESEC de

\footnotetext{
${ }^{2}$ A maior parte da APA da Baleia Franca encontra-se no município de Imbituba; a área integrante do território da Ilha de Santa Catarina é constituída apenas da ponta SW da mesma.

${ }^{3}$ A maior parte da APA de Anhatomirim encontra-se no município de Governador Celso Ramos; a área integrante do território da Ilha de Santa Catarina é constituída apenas do pontal NW da mesma e do canal de navegação entre ambos.
} 
Carijós, RESEX de Pirajubaé, REBIO Mar do Arvoredo ${ }^{4}$, UC do Desterro ${ }^{5}$ ), 02 estaduais (PE Serra do Tabuleiro ${ }^{6}$, PE Rio Vermelho), 09 municipais (PF Córrego Grande, PM Lagoa do Peri, PM Dunas da Lagoa da Conceição, PM Galheta, PM Lagoinha do Leste, PM Maciço da Costeira, PM Manguezal do Itacorubi, PM Ponta do Sambaqui, PU Morro da Cruz) e 02 particulares (RPPN Morro das Aranhas, RPPN Menino Deus) ${ }^{7}$.

Estas UCs recobrem parcela significativa do território insular da Ilha de Santa Catarina (aproximadamente 11.300 ha) e seus entornos, nos biomas marinho-costeiro e Mata Atlântica, cuja fisiografia abriga grande heterogeneidade espacial e biodiversidade, compreendendo um amplo e interconectado conjunto de ecossistemas, como a floresta ombrófila, os rios e ribeirões, a vegetação de restinga, os banhados, as lagoas costeiras, a laguna, os manguezais, as planícies intermareais, as dunas, as praias arenosas, os costões rochosos, as baías, as ilhotas, os recifes de coral e o ambiente marinho adjacente (NIEHUES, 2014: 47).

\section{Os Serviços Ecossistêmicos}

$\mathrm{Na}$ análise integrada destas diferentes unidades ambientais na Ilha de Santa Catarina e seus entornos, constataram-se grande diversidade de serviços ecossistêmicos e benefícios proporcionados, bem como de atores sociais e atividades envolvidas (ASMUS, SCHERER, OLIVEIRA, 2014: 05). Ao adaptar tal enfoque para as áreas destes ambientes circunscritas pelas referidas UCs, e condensar a análise dos serviços ecossistêmicos para o conjunto de unidades ambientais das mesmas, obteve-se uma visão abrangente do contexto (Tabela 1).

Tabela 1: Serviços ecossistêmicos e usos públicos nas UCs na Ilha de Santa Catarina

\begin{tabular}{|c|c|c|c|c|c|}
\hline Ecossistemas & Classificação & Serviços & Usos e benefícios & Atores sociais & Impactos \\
\hline $\begin{array}{l}\text { Floresta } \\
\text { ombrófila, } \\
\text { rios e } \\
\text { ribeirões, } \\
\text { restingas, } \\
\text { praias, } \\
\text { manguezais, } \\
\text { planícies }\end{array}$ & Suporte & $\begin{array}{l}\text { Matéria } \\
\text { orgânica, } \\
\text { diversidade de } \\
\text { habitas, } \\
\text { navegabilidade. }\end{array}$ & $\begin{array}{l}\text { Pesca, madeiras, } \\
\text { tanino, transporte, } \\
\text { qualidade do ar, } \\
\text { diluição, } \\
\text { circulação. }\end{array}$ & $\begin{array}{l}\text { Pescadores } \\
\text { artesanais e } \\
\text { industriais, } \\
\text { extrativistas, } \\
\text { cooperativas, } \\
\text { navegação } \\
\text { turística e } \\
\text { esportiva. }\end{array}$ & $\begin{array}{l}\text { Infraestrutura e } \\
\text { construções, } \\
\text { extração ilegal, } \\
\text { agropecuária, } \\
\text { mineração, turismo } \\
\text { e comércio de sol e } \\
\text { praia. }\end{array}$ \\
\hline $\begin{array}{l}\text { intermareais, } \\
\text { lagoas } \\
\text { costeiras, } \\
\text { laguna, } \\
\text { costões } \\
\text { rochosos, }\end{array}$ & Provisão & $\begin{array}{l}\text { Berçário } \\
\text { natural, } \\
\text { biomassa, } \\
\text { recurso hídrico. }\end{array}$ & $\begin{array}{l}\text { Pesca, } \\
\text { extrativismo, } \\
\text { abastecimento, } \\
\text { comunidade local. }\end{array}$ & $\begin{array}{l}\text { Pescadores } \\
\text { artesanais e } \\
\text { industriais, } \\
\text { extrativistas, } \\
\text { setor } \\
\text { gastronômico. }\end{array}$ & $\begin{array}{l}\text { Infraestrutura e } \\
\text { construções, } \\
\text { sobrepesca, } \\
\text { dragagens, } \\
\text { drenagem, } \\
\text { efluentes. }\end{array}$ \\
\hline
\end{tabular}

${ }^{4}$ A REBIO do Arvoredo Engloba águas dos municípios de Florianópolis, Governador Celso Ramos, Porto Belo, Bombinhas e Tijucas.

${ }^{5}$ A UC do Desterro é administrada pela UFSC - Universidade Federal de Santa Catarina.

${ }^{6}$ O PE Serra do Tabuleiro envolve os municípios de Palhoça, Santo Amaro da Imperatriz, Águas Mornas, São Bonifácio, São Martinho, Imaruí, Garopaba, Paulo Lopes e uma pequena parte (extremo sul) de Florianópolis.

${ }^{7}$ Categorias de UCs: APA - Área de Proteção Ambiental; ESEC - Estação Ecológica; PARNA - Parque Nacional; PE - Parque Estadual; PF - Parque Florestal; PM - Parque Municipal; PU - Parque Urbano; REBIO Reserva Biológica; RESEX - Reserva Extrativista; RPPN - Reserva Privada do Patrimônio Natural. 


\begin{tabular}{|l|l|l|l|l|l|}
\hline $\begin{array}{l}\text { baías, ilhotas, } \\
\text { mar } \\
\text { adjacente. }\end{array}$ & Regulação & $\begin{array}{l}\text { Ciclagem de } \\
\text { nutrientes, } \\
\text { estoque de } \\
\text { sedimentos, } \\
\text { proteção da } \\
\text { linha de costa, } \\
\text { clima. }\end{array}$ & $\begin{array}{l}\text { Qualidade da } \\
\text { agua, segurança } \\
\text { para ocupação, } \\
\text { proteção ao } \\
\text { fundeio, fixação } \\
\text { de encostas. }\end{array}$ & $\begin{array}{l}\text { Comunidade } \\
\text { local, setor } \\
\text { imobiliário. }\end{array}$ & $\begin{array}{l}\text { Infraestrutura e } \\
\text { construções, } \\
\text { dragagens, } \\
\text { efluentes, espécies } \\
\text { invasoras. }\end{array}$ \\
\cline { 3 - 6 } & Cultural & $\begin{array}{l}\text { Reprodução } \\
\text { cultural, } \\
\text { paisagem, } \\
\text { processo } \\
\text { histórico. }\end{array}$ & $\begin{array}{l}\text { Valor } \\
\text { contemplativo, } \\
\text { lazer, educação } \\
\text { ambiental, } \\
\text { esportes, } \\
\text { patrimônio } \\
\text { arqueológico, } \\
\text { mergulho. }\end{array}$ & $\begin{array}{l}\text { Comunidade } \\
\text { local, instituições } \\
\text { de ensino, trade } \\
\text { turístico, } \\
\text { operadoras de } \\
\text { mergulho, } \\
\text { IPHAN. }\end{array}$ & $\begin{array}{l}\text { Infraestrutura e } \\
\text { construções } \\
\text { urbanas, efluentes, } \\
\text { resíduos, } \\
\text { sobrepesca, choque } \\
\text { cultural. }\end{array}$ \\
\hline
\end{tabular}

Fonte: elaboração do autor, adaptado de ASMUS, SCHERER, OLIVEIRA, 2014.

\section{Conflitos e Impactos Socioambientais}

Neste contexto, pode-se melhor perceber alguns dos problemas de gestão envolvidos, como a similaridade e recorrência de forçantes preponderantes nos seus principais impactos socioambientais. Para tal, devem-se salientar alguns dos passivos ambientais da região (REIS, 2012:87); historicamente a Ilha de Santa Catarina sofreu um intenso processo de desmatamento ao longo do período colonial, com a quase total supressão da cobertura original de sua floresta ombrófila (CARUSO, 1983: 49), atualmente em regeneração após a decadência da atividade agrícola (basicamente na produção de farinha de mandioca) como ciclo econômico regional (CESCO, 2011: 12). Mais recentemente, outros ambientes têm sofrido grandes alterações, em função dos extensos aterros para expansão da infraestrutura urbana e transporte, no caso dos manguezais e planícies intermareais (DIEDERICHSEN, 2014: 31; PORTO FILHO et al., 2012: 09; PROCHNOW et al., 2009: 03) e da consolidação de novos loteamentos, condomínios e balneários, sobre as praias arenosas e restingas (OLIVEIRA, 2015: 41). Os ecossistemas costeiros e todo seu potencial de produção biológica vêm sendo severamente atingidos pela supressão de áreas de criadouros e de alimentação (ELLER et al, 2013: 10), pela pesca industrial predatória sobre os berçários, e ainda pela crônica poluição de efluentes orgânicos, em consequência da carência de saneamento básico; tal situação atinge incisivamente as comunidades remanescentes de pesca artesanal (CASTRO, 2008: 64), impondo grandes dificuldades a sua subsistência material e reprodução cultural. Atualmente, a Ilha de Santa Catarina estrutura sua economia na dupla função de cidade administrativa, como sede de grandes instituições públicas e empresas privadas (REIS, 2012: 62) e cidade-balneário, baseada no turismo de sol e praia (GUIMARÃES, 2006: 59; REIS, 2012: 62). 


\section{Os Usos Públicos}

Dentre os diferentes usos públicos dos serviços ecossistêmicos nas UCs da Ilha de Santa Catarina e entornos, cabe diferenciar alguns atores sociais e atividades mais representativas, nem sempre realizadas legalmente, ou ambientalmente referidas:

a) Extrativistas-dependentes: setores da população local, ambiental e culturalmente associados com a utilização de alguns dos espaços e recursos naturais proporcionados pelos ecossistemas, como os pescadores (artesanais e industriais) e os marisqueiros - catadores do berbigão Anomalocardia brasiliana, do mexilhão ou marisco-dapedra Perna perna e de outros macro invertebrados bentônicos. Além destes, a história regional registra os extrativistas de produtos vegetais (madeiras, tanino, carvão, palmito, xaxim e ervas medicinais ou decorativas), e outras formas de exploração de recursos animais (caça de subsistência, caça comercial da baleia e caieiras ${ }^{8}$ ), atividades atualmente proibidas;

b) Espaço-dependentes: setores da população local, comercialmente associados com determinados espaços do território (encostas de morros e campos litorâneos, praias, laguna), para o desenvolvimento de suas atividades econômicas (agropecuária, loteamentos e hotelaria, transporte hidroviário), respectivamente, agricultores familiares e pequenos pecuaristas, empreendimentos imobiliários e turísticos, cooperativas de barqueiros;

c) Espaço-beneficiários: setores da população local e externa, que mesmo não tendo uma dependência direta dos espaços do território, usufruem dos serviços ecossistêmicos dos mesmos, sejam como empreendedores (comércio de pescados, restaurantes, pousadas, transportes), como clientes destes (turistas, veranistas e população local), ou ainda como prestadores de serviços (guias de turismo, instrutores de mergulho) ou fornecedores de produtos a eles associados (artesãos, músicos, fotógrafos), dentre outros.

\section{Gestão das UCs}

Um dos traços característicos das referidas UCs é a predominância de unidades de "conservação integral", o que determina limites muito estreitos para a administração, com vistas à participação comunitária na gestão das mesmas. Esta ausência da sociedade nos processos decisórios na gestão das UCs só não é absoluta em face da (mínima) presença de unidades de "uso sustentável" - RESEX Pirajubaé (RIBAS, 2014: 39) e da admissão de representantes institucionais nos conselhos (consultivos, mas não deliberativos) das demais unidades. A complementaridade e, muitas vezes a contiguidade, das diferentes unidades ambientais dentre o conjunto de UCs da Ilha de Santa Catarina demanda uma visão e administração que contemple as suas estruturas e funções ecológicas e os serviços ecossistêmicos que as mesmas disponibilizam à sociedade, e dos usos públicos que a mesma deles faz. Por outro lado, o modelo excessivamente centralizado e burocrático das instituições gestoras destas UCs (ICMBio, FATMA, FLORAM) dificulta os esforços integradores entre as

\footnotetext{
${ }^{8}$ Caieiras: produção de cal, pela queima de grandes volumes de conchas de moluscos estuarinos e marinhos, geralmente utilizando como combustível a madeira obtida do corte das árvores dos manguezais.
} 
mesmas - apesar do reconhecimento quanto a sua pertinência (POLETTE et al., 2006: 46; MP-SPU-CTEPO SC, 2014: 17) e iniciativas neste sentido (ICMBio, sd 02;) - e a perspectiva de atuação conjunta com a sociedade (HENRICH, 2015: 38).

\section{$\underline{\text { Alternativas de gestão ambiental }}$}

Para ser viável e efetiva qualquer proposta de modelo alternativo para a gestão das UCs regionais deveria considerar o contexto atual, as dependências e singularidades socioeconômicas em relação aos espaços e recursos naturais, interpretando os usos públicos (devidamente regulados) das mesmas, não como obstáculos, mas como elementos potencializadores de outras formas de relações socioambientais. Um modelo alternativo de gestão destas UCs, integrando e complementando as equipes das instituições gestoras (superando a sobreposição de nichos e competências legais das mesmas), e inserindo as demandas, necessidades e expectativas das comunidades do entorno e da sociedade envolvente no seu planejamento cotidiano, poderia consolidar um processo de pertencimento social (MATOS, GUIMARÃES, 2008: 199) e contribuição para a sua efetividade. Diversos serviços ecossistêmicos proporcionados pelo seu mosaico de UCs poderiam vir a ser contemplados nos respectivos planos de gestão, autorizando e regulando as atividades socioeconômicas que deles se beneficiam, assim reduzindo a pressão antrópica sobre a base de sustentação dos ecossistemas regionais (VIVACQUA, 2005: 121), muitos expostos a grandes impactos e transformações, pelo incremento das demandas derivadas do crescimento socioeconômico da área metropolitana (BAPTISTA, 2008: 11).

Assim, por exemplo, um maior controle e monitoramento sobre a cadeia produtiva da pesca e da expansão imobiliária poderiam ser compensados com o estímulo a algumas das interfaces do turismo ecológico-cultural, promovendo o zoneamento espaço-temporal do território, de modo a incorporar os esportes radicais (surf, wind surf, sand board, escalada, voo livre, mergulho esportivo e científico), a educação ambiental (trilhas interpretativas, observação de espécies e comportamento animal - birdwatching, whale watching), a educação patrimonial (sítios arqueológicos, roteiros históricos e naufrágios), o patrimônio imaterial (música, danças, festas religiosas e gastronomia regional) e artístico-cultural (eventos e produções foto-videográficas, artes plásticas, cênicas e outras).

\section{CONCLUSÕES}

Constata-se que diversos dos problemas relativos à gestão dos usos públicos das UCs na Ilha de Santa Catarina e entornos assumem tal dimensão porque o modelo de gestão e manejo destas UCs, via de regra, ainda é compartimentalizado, mais focalizado nos aspectos jurídicos que as regulam, desconsiderando alguns dos processos e peculiaridades dos seus ecossistemas e das comunidades do entorno, especialmente quando consideramos a dinâmica dos processos socioambientais, extremamente diversos e catalisados por forçantes externas em rápida e contínua transformação. A implantação efetiva de um sistema de gestão integrado 
e participativo do mosaico de UCs na Ilha de Santa Catarina e seus entornos poderia contribuir eficazmente para os objetivos de garantir a existência e a funcionalidade de uma amostra representativa do conjunto de ecossistemas da região, com toda a biodiversidade associada, bem como poderia também viabilizar a reprodução cultural e inserção das comunidades tradicionais vinculadas a estes territórios e a alguns dos seus recursos naturais, e da sociedade envolvente, regulamentando os usos públicos dos seus espaços e recursos.

\section{REFERÊNCIAS BIBLIOGRÁFICAS}

ALMEIDA, F. B. Análise da Efetividade de Manejo em uma Área Importante para a Conservação das Aves (IBA) e da Biodiversidade: o caso do Parque Estadual da Serra do Tabuleiro, SC, Brasil. Dissertação de Mestrado (Programa de Pós-Graduação em Geografia). Florianópolis: UFSC - Universidade Federal de Santa Catarina, março/2015.

ASMUS, M. L.; SCHERER, M.; OLIVEIRA, T. C. Gestão com Base Ecossistêmica (EGB): influencia na Ilha de Santa Catarina, SC. In: XXVI Semana Nacional de Oceanografia (Guaratuba, PR: 28/Setembro- 04/Outubro/2014). UFPR - Universidade Federal do Paraná.

BRASIL. Decreto de 14 de Setembro de 2000 (criação da Área de Proteção Ambiental APA da Baleia Franca, litoral de Santa Catarina). Brasília: Presidência da República, 2000 .

BAPTISTA, S. R. Metropolitanization and forest recovery in southern Brazil: a multiscale analysis of the Florianópolis city-region, Santa Catarina State, 1970 to 2005. Ecology and Society 13 (02): 05, 2008. [online] URL: http://www.ecologyandsociety.org/vol13/iss2/art5/

CASTRO, A. G. S. O Uso dos Recursos Naturais e o Desafio para a Conservação da Biodiversidade Marinha: mudanças e conflitos em uma comunidade pesqueira na Ilha de Santa Catarina, Brasil. Tese de Doutorado (Programa de Pós-Graduação em Ecologia). Porto Alegre: UFRGS - Universidade Federal do Rio Grande do Sul, 2008 (212 p).

CARUSO, M. M. L. O Desmatamento da Ilha de Santa Catarina: de 1500 aos dias atuais. Florianópolis: Ed. UFSC, 1983 (160 p).

CESCO, S. Agricultura e Transformação Ambiental: o caso da Ilha de Santa Catarina no século XIX $(15$ p). In: Anais do XXVI Simpósio Nacional de História. São Paulo: ANPUH, julho/2011.

DIEDERICHSEN, S. DuPrey. Percepção dos atores sociais frente aos problemas socioambientais da bacia hidrográfica do Rio Tavares como subsídio à estratégia de gestão costeira integrada. Dissertação de Mestrado (Programa de Pós-Graduação em Geografia). Florianópolis: UFSC - Universidade Federal de Santa Catarina, 2014.

ELLER, J. R. G.; SANTOS, L.; NASCIMENTO, R. da S. Análise Ambiental do Manguezal do Rio Tavares, Florianópolis (SC, Brasil). In: Anales del XIV ${ }^{\circ}$ EGAL - Encuentro de Geografos de America Latina (Lima, Perú: 02-12/Abril/2013).

FATMA. Parque Estadual da Serra do Tabuleiro. Florianópolis: Fundação Estadual de Tecnologia e Meio Ambiente (sd). Disponível em: http://www.fatma.sc.gov.br/conteudo/parque-estadual-da-serra-do-tabuleiro (acesso em: 06/Setembro/2014). 
FLORIPA AMANHA. Unidades de Conservação de Florianópolis e Região. Florianópolis, SC (sd). Disponível em: http://floripamanha.org/tag/unidade-de-conservacao (acesso em: 10/Abril/2015).

GUIMARÃES, V. M. Turismo e Modernidade em tempos de globalização: o turismo e os turistas na Barra da Lagoa (pp: 55-67). In: RIAL, Carmen; GODIO, Matias (Orgs.). Pesca e Turismo: etnografias da globalização no litoral do Atlântico Sul. Florianópolis: NUPPECFH-UFSC, 2006 (240 p).

HENRICH, M. E. Gestão Integrada e Participativa de Unidades de Conservação: os desafios do Parque Estadual da Serra do Tabuleiro (SC) e seus territórios. Dissertação de Mestrado Profissional (Programa de Pós-Graduação em Planejamento Territorial e Desenvolvimento Socioambiental). Florianópolis: UDESC - Universidade do Estado de Santa Catarina, 2015.

IBAMA. Plano de Manejo da Reserva Biológica Marinha do Arvoredo, SC (Encarte 01 Contextualização). Brasília: IBAMA - Instituto Brasileiro do Meio Ambiente e Recursos Naturais Renováveis, 2004 (295 p).

ICMBIO. Unidades de Conservação no Bioma Marinho Costeiro. Brasília: ICMBio Instituto Chico Mendes de Conservação da Biodiversidade, sd 01. http://www.icmbio.gov.br/portal/biodiversidade/unidades-de-conservacao/biomas-

brasileiros/marinho/unidades-de-conservacao-marinho.html (acesso em: 06/Setembro/2014).

ICMBIO. Conservação da Biodiversidade na Zona Costeira e Marinha de Santa Catarina. Brasília: MMA - Ministério do Meio Ambiente, ICMBio - Instituto Chico Mendes de Conservação da Biodiversidade; Florianópolis: Coordenação Regional do ICMBio SC, sd $02(36 \mathrm{p})$.

ICMBIO. Plano de Manejo da APA de Anhatomirim, SC. Encarte 01 - Contextualização. Brasília: ICMBio - Instituto Chico Mendes de Conservação da Biodiversidade, 2013 (64 p).

KOSMUS, M.; RENNER, I.; ULRICH, S. Integração de Serviços Ecossistemicos ao Planejamento do Desenvolvimento. Brasília: GIS (Serviço Alemão para Cooperação Internacional) - Projeto "Inovação Futura, Biodiversidade e Serviços Ecossistemicos", outubro de 2012 (92 p). Disponível em: http://www.giz.de/expertise/downloads/giz2012-ptservicos-ecossistemicos.pdf

MATOS, M. P.; GUIMARÃES, S. T. L. A Sensibilidade do Lugar: uma proposta metodológica de aplicação da percepção ambiental na gestão da zona costeira em áreas urbanas. OLAM - Ciência e Tecnologia (Rio Claro, SP), 08 (03): 195-214, Jul-Dez/2008.

MP-SPU-CTEPO SC. Planos de Gestão Integral das Orlas Marítimas: Projeto Orla SC. Brasília: Ministério Público Federal; Florianópolis: Serviço de Patrimônio da União SC, Comissão Técnica Estadual do Projeto Orla SC, 2014 (38 p).

NIEHUES, J. P. Sistema Ambiental Ilha de Santa Catarina: ecossistemas dominantes, componentes e processos. Monografia de Graduação (Curso de Bacharelado em Ciências Biológicas, UFSC). Florianópolis: UFSC - Universidade Federal de Santa Catarina, dezembro/2014.

OLIVEIRA, T. C. R. Uso e Qualidade das Praias Arenosas da Ilha de Santa Catarina: bases para seu planejamento ambiental. Dissertação de Mestrado (Programa de Pós- 
Graduação em Geografia). Florianópolis: UFSC - Universidade Federal de Santa Catarina, 2015 (93 p).

PMF. Unidades de Conservação. Florianópolis: Prefeitura Municipal de Florianópolis, SC

(sd). Disponível em:

http://www.pmf.sc.gov.br/entidades/floram/index.php?cms=unidades+de+conservacao\&menu =6 (acesso em: 06/Setembro/2014).

POLETTE, M.; REBOUÇAS, G. N. M.; FILARDI, A. C. L.; VIEIRA, P. F. Rumo à Gestão Integrada e Participativa de Zonas Costeiras no Brasil: Percepções da Comunidade Científica e do Terceiro Setor. Gestão Costeira Integrada (Itajaí), 05 (04): 43-48, 2006.

PORTO FILHO, E.; WASKOW, L. B.; SILVA, A. W. L.; SIERRA, E. J. S. Diagnóstico Socioambiental e Perspectivas de Sustentabilidade para a Região de Entorno do Rio Papaquara, Florianópolis, SC. In: III Congresso Brasileiro de Gestão Ambiental (Goiânia/GO: 19-22/Novembro/2012), 13 p.

PROCHNOW, R. M.; DAL SANTO, M. A.; AMEY, R. A expansão das cidades sobre a Zona Costeira: estudo de caso de Florianópolis, BR, e Boston, USA. In: $12^{\circ} E G A L$ Encuentro de Geógrafos de América Latina (Montevideo, 2009). Disponível em: http://www.geolab.faed.udesc.br/publicacoes/Artigos_Egal/Prochnow_Egal.pdf (acesso em: 19/Outubro/2014).

REIS, A. F. Ilha de Santa Catarina: permanências e transformações. Florianópolis: Ed. UFSC (Coleção Urbanismo e Arquitetura da Cidade), 2012 (284 p).

RIBAS, L. C. (Org.). A Reserva Extrativista Marinha do Pirajubaé: sujeitos, memórias e saberes etnobiológicos. Florianópolis: IFSC, 2014 (168 p).

SANTOS, R. F. O Contexto Histórico da Definição Conceitual de Serviços Ecossistemicos (2014, 51 p). Disponível em: www.fapesp.br/eventos/2014/02/biota/rozely_ferreira.pdf

TIRLONI, D. Unidades de Conservação de Florianópolis. Florianópolis, SC (01 de abril de 2013). Disponível em: http://www.blogdotirloni.com.br/meio-ambiente/unidades-deconservacao-florianopolis/ (acesso em: 10/Abril/2015).

VIVACQUA, M. Conflitos Socioambientais no Litoral de Santa Catarina: o caso da Reserva Biológica Marinha do Arvoredo. Dissertação de Mestrado (Programa de pósGraduação em Sociologia Política). Florianópolis: UFSC - Universidade Federal de Santa Catarina, 2005 (114 p).

YIN, R. K. Estudo de caso: planejamento e métodos. 3. ed. Porto Alegre: Bookman, 2005. 